\title{
Human Endometrial Matrix Metalloproteinase-2, a Putative Menstrual Proteinase Hormonal Regulation in Cultured Stromal Cells and Messenger RNA Expression During the Menstrual Cycle
}

\author{
Juan C. Irwin, ${ }^{*}$ David Kirk, ${ }^{\ddagger}$ Ralph B. L. Gwatkin, ${ }^{\S}$ Marc Navre, $\|$ Paul Cannon, ${ }^{\|}$and Linda C. Giudice* \\ $*$ Department of Gynecology and Obstetrics, Stanford University Medical Center, Stanford, California 94305; ${ }^{*}$ Huntington Medical \\ Research Institutes, Pasadena, California 91101; ${ }^{\S}$ Department of Reproductive Biology, Case Western Reserve University School of

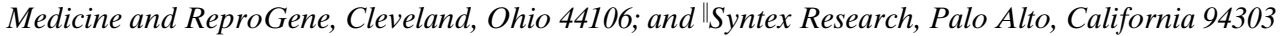

\begin{abstract}
Proteinases are likely effectors of endometrial menstrual breakdown. We have investigated proteinase production by human endometrial stromal cells subjected in vitro to progesterone $(\mathrm{P})$ withdrawal, the physiologic stimulus for menstruation. Culture media of cells exposed to estradiol, $P$, or estradiol plus $P$ had low levels of proteolytic activity similar to cultures maintained in the absence of steroids. $P$ withdrawal, or addition of RU486 to P-treated cultures, stimulated proteinase secretion. The stromal cell proteinase was characterized by gelatin zymography, inhibitor profile, and organomercurial activation, as a metalloproteinase present mostly as a 66-kD proenzyme with lower levels of a 62$\mathrm{kD}$ active form. The $\mathrm{P}$ withdrawal-induced metalloproteinase was identified as matrix metalloproteinase-2 (MMP-2) by Western blotting. The increase of MMP-2 induced by $P$ withdrawal was associated with the metalloproteinasedependent breakdown of stromal cultures, involving dissolution of extracellular matrix and dissociation of stromal cells. Northern analysis showed the differential expression of MMP-2 mRNA in late secretory phase endometrium. These findings are consistent with the involvement of stromal cell-derived MMP-2 in the proteolysis of extracellular matrix promoting cyclic endometrial breakdown and the onset of menstrual bleeding. (J. Clin. Invest. 1996. 97:438447.) Key words: endometrium - menstruation - uterine bleeding $\bullet$ gelatinase $\mathrm{A} \cdot$ type IV collagenase
\end{abstract}

\section{Introduction}

During normal ovulatory cycles the human endometrium undergoes complex changes involving the proliferation and differentiation of both epithelial and stromal components in preparation for embryo implantation (1). In nonconception cycles the regression of the corpus luteum causes circulating estradiol $(\mathrm{E})^{1}$ and progesterone $(\mathrm{P})$ levels to decline, initiating a

Address correspondence to Juan C. Irwin, Department of Gynecology/Obstetrics, East Pavilion HH 333, Stanford Medical Center, Stanford, CA 94305. Phone: 415-723-0958; FAX: 415-723-7737.

Received for publication 21 September 1994 and accepted in revised form 9 October 1995.

1. Abbreviations used in this paper: APMA, 4-aminophenylmercuric acetate; E, estradiol; MMP, matrix metalloproteinase; $\mathrm{P}$, progesterone.

J. Clin. Invest.

(C) The American Society for Clinical Investigation, Inc.

0021-9738/96/01/438/10 \$2.00

Volume 97, Number 2, January 1996, 438-447 complex process ultimately leading to the breakdown and shedding of the endometrial functionalis. This unique event of the menstrual cycle has been traditionally viewed as the result of ischemic necrosis caused by vasospasm of the endometrial spiral arteries (2). However, the precise cellular and molecular mechanisms underlying the menstrual breakdown of the endometrium are poorly understood. Menstrual disturbances constitute an important clinical problem (3), being a major cause for discontinuing or reducing the acceptability of contraceptive methods (4), and insufficient knowledge of the basic mechanisms underlying the process of menstruation has been a serious obstacle in the search for solutions to these problems.

The involvement of proteolytic enzymes in menstruation was first proposed implicating lysosomal enzymes in endometrial breakdown $(5,6)$. However, recent studies have failed to provide conclusive evidence of the involvement of lysosomal enzymes in the initiation of menstruation (7). The plasminogen activator/plasmin system (reviewed in reference 8) represents another group of proteinases potentially relevant to menstrual breakdown. Plasminogen activators are serine proteinases that activate plasminogen generating the fibrinolytic enzyme plasmin, a broad spectrum serine proteinase which can cleave extracellular matrix proteins and also activate zymogens of other matrix-degrading proteinases. The participation of plasminogen activators has been proposed in oocyte maturation, ovulation, and trophoblast invasion, and the finding of increased plasminogen activator activity in extracts from menstrual phase endometria (9) is suggestive of their involvement in tissue breakdown. Other likely effectors of endometrial menstrual breakdown are the matrix metalloproteinases (MMPs), a multigene family of zinc-requiring enzymes that degrade components of the extracellular matrix, playing a central role in a variety of processes involving tissue remodeling and breakdown (10-12). MMPs are secreted as proenzymes that undergo activation to a catalytically active form and are inhibited by specific tissue inhibitors of metalloproteinases. In female reproductive tissues, MMPs have been implicated in physiological processes such as ovulation $(13,14)$, embryo implantation (15), and postpartum uterine involution $(16,17)$. MMPs have been identified in human endometrial tissue (18), as well as in endometrial explant and stromal cell cultures (19, 20). In human endometrium, mRNAs encoding the various MMPs are expressed in cycle-specific patterns, suggesting the involvement of MMPs in processes of growth and remodeling during the menstrual cycle (21).

Decidualized stromal cells become prominent in late secretory endometrium (1), where they are spatially and temporally positioned at the time of declining $\mathrm{P}$ levels to participate in the events leading to menstrual breakdown. Human endometrial stromal cells decidualize in culture in response to $\mathrm{P}$, expressing a variety of cellular functions characteristic of the cycling en- 
dometrium (22-24). Therefore, we sought to investigate the production of extracellular matrix-degrading proteinases by decidualized endometrial stromal cell cultures subjected to $\mathrm{P}$ withdrawal, as an in vitro model for endometrial breakdown.

\section{Methods}

Tissues. Tissues were obtained in accordance with the guidelines of The Declaration of Helsinki after informed consent and with approval by the Stanford University Human Subjects Committee. Histologically normal endometria $(n=18)$ obtained from biopsy or hysterectomy specimens were dated by histological criteria (1). Early pregnancy decidua was obtained by uterine curettage at the time of laparoscopy for ectopic gestation. Term placentae, obtained at the time of cesarean section, were stripped of maternal decidua. Samples used for RNA isolation were immediately frozen in liquid nitrogen and stored at $-70^{\circ} \mathrm{C}$. Samples used for isolation and culture of endometrial cells were collected in DME (GIBCO BRL, Grand Island, NY).

Cell Cultures. Human endometrial stromal cell cultures established and passaged as described (22) contained $<0.1 \%$ of epithelial and vascular cell contaminants (22), and no macrophage contamination as shown by screening with antibodies Leu-M3 and Leu-M5 (Beckton Dickinson Co., Mountain View, CA). Stromal cells (passages 1-7) grown to confluence in DME containing bovine insulin ( $5 \mu \mathrm{g} / \mathrm{ml}$; Sigma Chemical Co., St. Louis, MO) and 10\% charcoalstripped FBS (GIBCO), were rinsed and treated with steroids (10-30 nM E, 0.1-1 $\mu$ M P, or E+P, all from Sigma Chemical Co.) or vehicle $(0.1 \%$ ethanol) in the above serum-containing medium or in serumfree medium supplemented with BSA, insulin, transferrin, and EGF (23). Culture media were renewed every $2-3$ d. For hormonal withdrawal, after $8-16 \mathrm{~d}$ of steroid treatment cultures were rinsed three times and maintained in serum-free medium without steroids. Steroids (10-30 nM E, 0.1-1 $\mu \mathrm{M} \mathrm{P}, 0.3-1 \mu \mathrm{M}$ medroxyprogesterone acetate, $0.3-1 \mu \mathrm{M}$ norethindrone, $1 \mu \mathrm{M} 17 \alpha$-hydroxyprogesterone, 30 $\mathrm{nM}$ dexamethasone, $0.1 \mu \mathrm{M} 5 \alpha$-dihydrotestosterone; Sigma), RU486 (0.3-1 $\mu \mathrm{M}$, Roussel-UCLAF, Romainville, France), or inhibitors (10$20 \mu \mathrm{M}$ cycloheximide, $1 \mathrm{mM}$ benzamidine, $100 \mu \mathrm{g} / \mathrm{ml}$ soybean trypsin inhibitor, $0.3 \mathrm{mM}$ leupeptin, $1.5 \mu \mathrm{M}$ pepstatin, $200 \mu \mathrm{g} / \mathrm{ml} \alpha_{2}$-macroglobulin, 10-25 $\mu \mathrm{M}$ 1,10-phenanthroline, $20 \mathrm{mM} \epsilon$-aminocaproic acid, $10 \mathrm{U} / \mathrm{ml}$ hirudin, Sigma) were added as indicated to the culture medium which was renewed every $24-48 \mathrm{~h}$. Cultures were viewed by phase contrast microscopy, and conditioned media were collected, centrifuged, and stored at $-70^{\circ} \mathrm{C}$. Cells were counted on a Coulter counter after trypsinization. Endometrial glands (25) were cultured in DME with $5 \mu \mathrm{g} / \mathrm{ml}$ insulin and 5\% FBS for $3 \mathrm{~d}$, followed by serumfree medium with $1 \mathrm{mg} / \mathrm{ml} \mathrm{BSA,} 5 \mu \mathrm{g} / \mathrm{ml}$ transferrin, and $100 \mathrm{ng} / \mathrm{ml}$ insulin. Human neonatal skin fibroblasts established and passaged as described (26) and the endometrial adenocarcinoma cell line HEC-1-A (American Type Culture Collection, Rockville, MD) were grown to confluence in DME with $10 \%$ FBS, rinsed, and maintained in serumfree medium. Conditioned media were collected as described above.

Scanning electron microscopy. Stromal cells cultured on 13-mm round glass coverslips were processed for scanning electron microscopy as described (25), and examined in a scanning electron microscope (JSM-35; JEOL U.S.A. Inc., Peabody, MA) at an accelerating voltage of $20 \mathrm{kV}$ and a specimen tilt angle of $45^{\circ}$.

Proteinase assay. Proteolytic activity was measured in 1- or 2-dconditioned media (0.1-0.6 ml) using Azocoll (Calbiochem Corp., San Diego, CA) as substrate (27). Unless noted otherwise, latent enzyme was activated adding $0.5 \mathrm{mM} 4$-aminophenylmercuric acetate (APMA) to the assay. As indicated, $10 \mathrm{mM}$ benzamidine, $100 \mu \mathrm{g} / \mathrm{ml}$ soybean trypsin inhibitor, $10 \mathrm{mM}$ leupeptin, $10 \mathrm{mM} N$-ethylmaleimide, $25 \mu \mathrm{M}$ pepstatin, $250 \mu \mathrm{g} / \mathrm{ml} \alpha_{2}$-macroglobulin, $10 \mathrm{mM}$ EDTA, $10 \mathrm{mM}$ 1,10-phenanthroline, $2 \mathrm{mM}$ PMSF, or vehicle (water, ethanol, or methanol) were added to the assay. One unit of activity $=$ hydrolysis of $1 \mu \mathrm{g}$ of Azocoll per minute at $37^{\circ} \mathrm{C}$. For comparisons, enzyme activities were normalized for cell number and time of media conditioning.

Substrate gel analysis. Proteinases in 1- or 2-d-conditioned media $(10-25 \mu \mathrm{l})$ were visualized by gelatin or casein zymography essentially as described (28). After nonreducing electrophoresis on $10 \%$ polyacrylamide-SDS gels (29) containing $0.1 \%$ gelatin or casein, gels were soaked $1 \mathrm{~h}$ in $2.5 \%$ Triton X-100, incubated $2-24 \mathrm{~h}$ at $37^{\circ} \mathrm{C}$ in $0.05 \mathrm{M}$ Tris, pH $8,5 \mathrm{mM} \mathrm{CaCl}_{2}, 0.02 \% \mathrm{NaN}_{3}$, and stained with $0.5 \%$ Coomassie blue R-250, 10\% acetic acid, 30\% methanol. Inhibitors (5 mM PMSF, $5 \mathrm{mM}$ 1,10-phenanthroline, $0.1 \mathrm{mM}$ pepstatin, $5 \mathrm{mM}$ $p$-chloromercuribenzoate) were added during incubation as indicated.

Western immunoblot analysis. A monospecific antibody to MMP-2 was raised in rabbits with the approval of the Syntex Institute Animal Care Use Committee. Animals were immunized with a synthetic 20amino acid peptide corresponding to a region of the $\mathrm{COOH}$-terminal domain of MMP-2 (residues 472-490 with an additional COOH-terminal cysteine for conjugation to a carrier protein) that does not show homology with other MMPs and is present in both the proenzyme and the active form (30). Conditioned media concentrated using centricon-10 or centriprep-10 devices (Amicon Corp., Danvers, MA) were subjected to electrophoresis on $10 \%$ polyacrylamide-SDS gels (29) with or without $25 \mathrm{mM}$ dithiothreitol (Sigma), and transferred to nitrocellulose (31). All following incubation and washing steps were in $0.15 \mathrm{M} \mathrm{NaCl}, 0.01 \mathrm{M}$ Tris, $\mathrm{pH} 7.4,0.1 \%$ Tween-20. Membranes were incubated $2 \mathrm{~h}$ in $5 \%$ nonfat milk, followed by $1 \mathrm{~h}$ in anti-MMP-2 (1:1000), and $1 \mathrm{~h}$ in peroxidase-conjugated donkey antirabbit Ig (Amersham Corp., Arlington Heights, IL) (1:300-1:2,000), being washed three times between incubations. Immune complexes were visualized by enhanced chemiluminescence using enhanced chemiluminescence reagents from Amersham Corp., followed by exposure to XAR film (Eastman Kodak, Rochester, NY).

Northern blot analysis. A cDNA probe corresponding to nucleotides 1410-1950 of the MMP-2 cDNA sequence (32) was used for Northern blot hybridization. RNA from A2058 human melanoma cells was reverse transcribed into cDNA using an oligo dT primer and amplified by PCR with a primer pair corresponding to nucleotides 1391-1412 of the MMP-2 cDNA sequence (32), containing an internal BglII site, and the complement of nucleotides 1927-1948 with an additional EcoRI site as part of a $5^{\prime}$ extension. PCR was run $40 \mathrm{cy}-$ cles: $94^{\circ} \mathrm{C} 1 \mathrm{~min}, 60^{\circ} \mathrm{C} 2 \mathrm{~min}, 72^{\circ} \mathrm{C} 3 \mathrm{~min}$, in $100 \mu l$ reaction vol containing $1 \mu \mathrm{M}$ of each primer, $2.5 \mathrm{mM} \mathrm{MgCl}_{2}$, and $0.25 \mathrm{mM}$ deoxynucleotide triphosphates. A 550-bp band was gel isolated, digested with EcoRI and BglII, and subcloned into the EcoRI and BamHI sites of pBluescriptSK (Stratagene Inc., La Jolla, CA). The 540-bp BamHIEcoRI fragment was labeled with ${ }^{32} \mathrm{P}$ by random priming. Total RNA was isolated from tissues by a modification of the guanidinium isothiocyanate- $\mathrm{LiCl}$ precipitation method (33) as described previously (34). RNA samples $(20 \mu \mathrm{g})$ were size fractionated by $1.2 \%$ agarose/formaldehyde gel electrophoresis, transferred to nitrocellulose, and the filter hybridized with the human MMP-2 cDNA probe as described (34). After exposure to XAR film, the MMP-2 probe was stripped and blots hybridized with a ${ }^{32} \mathrm{P}$-labeled $\beta$-actin cDNA probe.

Densitometry. Zymograms, Western, and Northern blots, were analyzed on a PDI Desk Top Scanner (Protein DNA ImageWare Systems, Huntington Station, NY). Standard curves using known amounts of purified MMP-2 were run in parallel with samples of conditioned media to verify that measured band densities were in the linear range of the assay for both zymograms $(0.5-20 \mathrm{ng})$ and Western blots $(20-500 \mathrm{ng})$. Levels of 66/62-kD gelatinase and immunoreactive MMP-2 in conditioned media were estimated converting measured band densities to nanograms of enzyme using the standard curve. MMP-2 was purified from human umbilical vein endothelial cell cultures by zinc chelate and gelatin affinity chromatography (32) with a final passage through a lentil lectin affinity column. For Northern blots, densities of MMP- 2 and $\beta$-actin bands were used to calculate the MMP- $2 / \beta$-actin hybridization ratio for each sample. When autoradiographs from two different exposure times for each MMP-2 and $\beta$-actin were used to calculate these ratios, relative differences be- 
tween high and low MMP-2/ $\beta$-actin hybridization ratios did not change as a function of film exposure time, indicating measured band densities were within the linear phase of film exposure.

Statistics. Experimental variables were tested in duplicate or triplicate cultures. One-way ANOVA was used for statistical evaluation of data, and significance of the differences between groups was determined by Dunnett's or Scheffe's test as appropriate, with $P<0.05$ considered significant.

\section{Results}

Hormonal regulation of metalloproteinase activity in endometrial stromal cultures. Proteolytic activity was examined in human endometrial stromal cell cultures exposed to E plus $\mathrm{P}$ for $14 \mathrm{~d}$, followed by withdrawal of the steroid hormones in order to simulate the hormonal changes that precede menstruation in normal ovulatory cycles. Conditioned medium was collected at various times during the course of the experiment, and proteolytic activity was assayed using as substrate Azocoll, which can be digested by a variety of proteinases. Since MMPs may be present as inactive zymogens, Azocoll proteolysis was also assayed in the presence of the organomercurial APMA, a known activator of latent MMPs $(11,30,35)$. Steroid withdrawal induced a major increase of proteolytic activity in stromal cultures, that was only evident after APMA activation (Fig. $1 \mathrm{~A}$ ). The levels of proteolytic activity measured in conditioned medium without organomercurial activation were very low or undetectable throughout the course of steroid treatment and withdrawal. Proteolytic activity of APMA-activated medium was also low during the $14 \mathrm{~d}$ of exposure to steroids but increased sharply $4 \mathrm{~d}$ after steroid withdrawal to peak on day 6 , followed by a decrease $8 \mathrm{~d}$ after discontinuing steroids.

Inhibitor studies characterized the steroid withdrawalinduced proteolytic activity as a metalloproteinase, suggesting its identity as an MMP. As shown in Fig. $1 \mathrm{~B}$, over $95 \%$ of the activity was present in latent form that was activated by APMA. The activated enzyme was significantly inhibited $(P<$ 0.01 ) by the broad spectrum inhibitor $\alpha 2$-macroglobulin, and by inhibitors of metalloproteinase activity such as EDTA, and 1,10-phenanthroline. In contrast, inhibitors of serine- (benzamidine, soybean trypsin inhibitor, PMSF), cysteine- (leupeptin, $N$-ethylmaleimide), and aspartic- (pepstatin) proteinases had no significant effect on its activity $(P>0.05)$.

The individual roles of $\mathrm{E}$ and $\mathrm{P}$ in regulating metalloproteinase activity were investigated exposing stromal cultures to either $\mathrm{E}, \mathrm{P}$, or $\mathrm{E}+\mathrm{P}$ for $14 \mathrm{~d}$, followed by withdrawal of the steroid hormones. Fig. $2 A$ shows the levels of proteolytic activity in APMA-activated conditioned media from such steroidtreated cultures and from control cultures maintained in the absence of steroids. Stromal cells did not produce high levels of proteolytic activity in the absence of steroids, and exposure to $\mathrm{P}$ followed by its withdrawal was required to stimulate metalloproteinase production. The only effect of $\mathrm{E}$ was to increase the magnitude of the response when used in combination with $\mathrm{P}$, such that optimal stimulation was obtained when cultures received $\mathrm{E}+\mathrm{P}$ followed by their withdrawal. In both $\mathrm{P}$ and $\mathrm{E}+\mathrm{P}$ treated cultures, proteolytic activity returned to baseline levels 8-10 d after steroid withdrawal.

To further assess the hormonal regulation of metalloproteinase activity, as well as its dependence on protein synthesis, stromal cells exposed to E $+\mathrm{P}$ for $12-14 \mathrm{~d}$, were cultured for an additional $4 \mathrm{~d}$ in the absence of steroids or in the presence
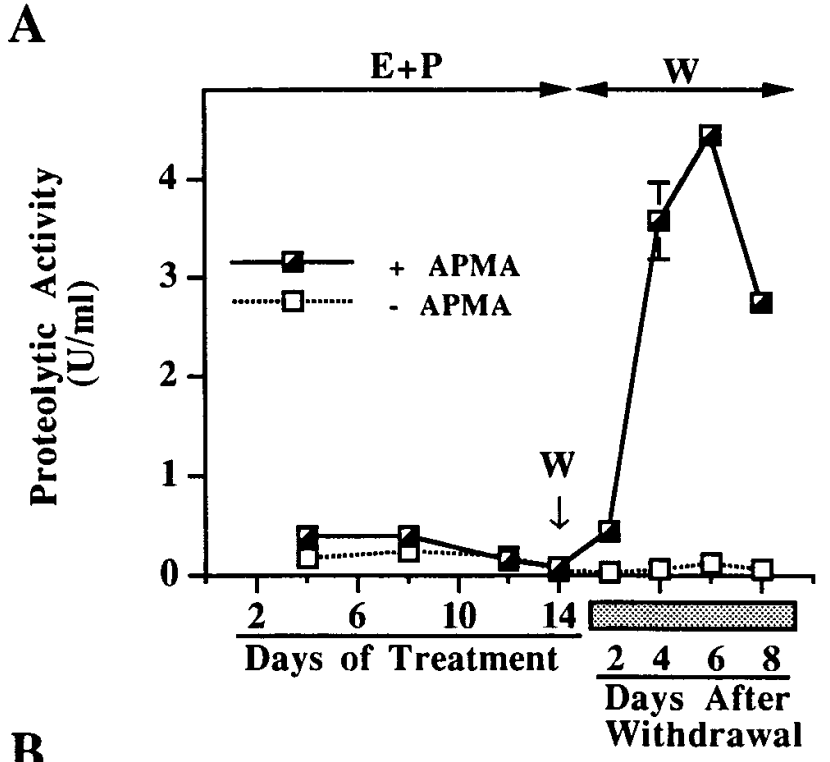

B

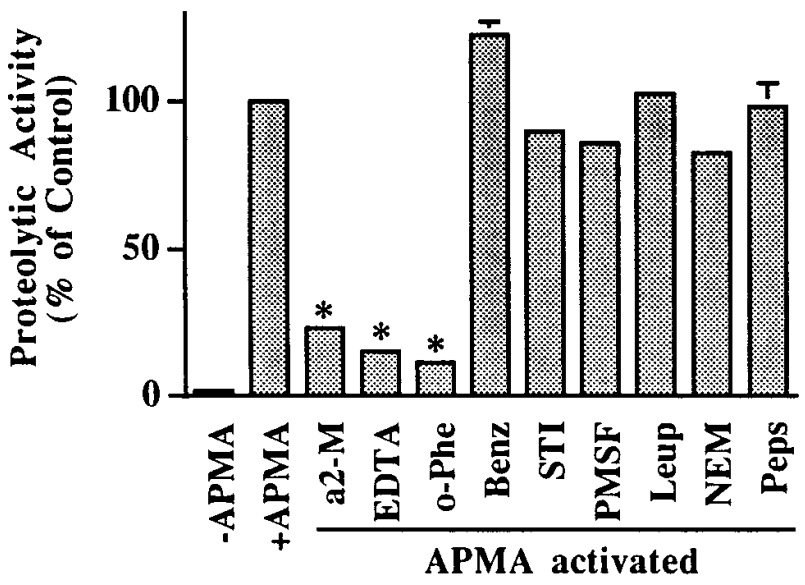

Figure 1. Human endometrial stromal cells were cultured $14 \mathrm{~d}$ in EGF-supplemented serum-free $(A)$ or serum-supplemented $(B)$ medium containing $10 \mathrm{nM} \mathrm{E}+1 \mu \mathrm{M} \mathrm{P}(\mathrm{E}+\mathrm{P})$, followed by steroid withdrawal $(W)$ as described in Methods. $(A)$ Effects of steroid withdrawal on proteolytic activity. Proteolytic activity of $2 \mathrm{~d}$-conditioned media collected at the indicated times was assayed in the absence ( - APMA) or presence (+ APMA) of $0.5 \mathrm{mM}$ APMA. The day of steroid withdrawal $(W)$ is indicated by the arrow. Values are the mean \pm SEM (bars) of duplicate cultures. (B) Inhibitor profile of steroid withdrawal-induced proteolytic activity. Proteolytic activity of 2 $\mathrm{d}$-conditioned media collected $4 \mathrm{~d}$ after hormonal withdrawal was assayed without APMA or with $0.5 \mathrm{mM}$ APMA alone $(A P M A)$, or in the presence of $250 \mu \mathrm{g} / \mathrm{ml} \alpha_{2}$-macroglobulin $(\alpha 2-\mathrm{M}), 10 \mathrm{mM}$ EDTA, $10 \mathrm{mM}$ 1,10-phenanthroline (o-Phe), $10 \mathrm{mM}$ benzamidine (Benz), 100 $\mu \mathrm{g} / \mathrm{ml}$ soybean trypsin inhibitor $(S T I), 2 \mathrm{mM}$ PMSF, $0.2 \mathrm{mM}$ leupeptin (Leup), $10 \mathrm{mM} N$-ethylmaleimide (NEM), or $25 \mu \mathrm{M}$ pepstatin (Peps). Values are the mean \pm SEM (bars) of duplicates expressed as the percentage control values. Mean activities (units) for controls were 0.89 (no vehicle), 0.90 ( $10 \%$ water), 0.78 ( $2.5 \%$ ethanol), and 0.86 ( $2.5 \%$ methanol). Statistical analysis was performed using oneway ANOVA and Scheffe's test. Differences between inhibitor and their respective control groups were not significant $(P>0.05)$ except where indicated $\left({ }^{*} P<0.01\right)$. 


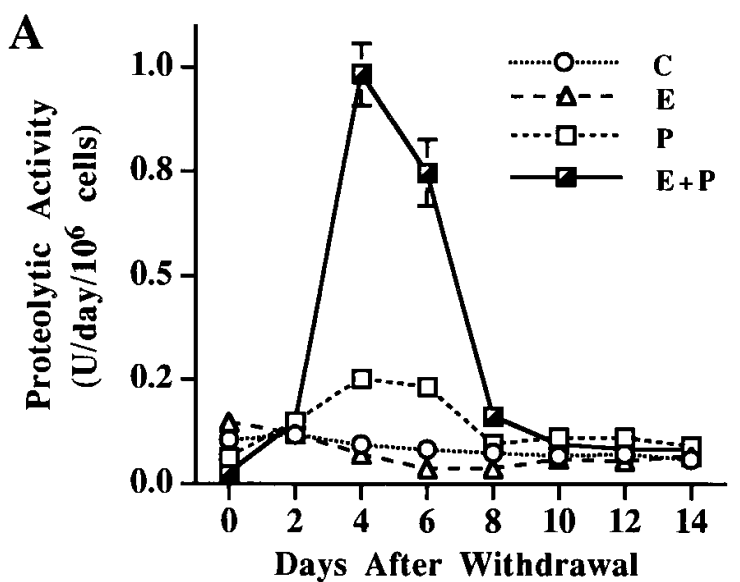

B

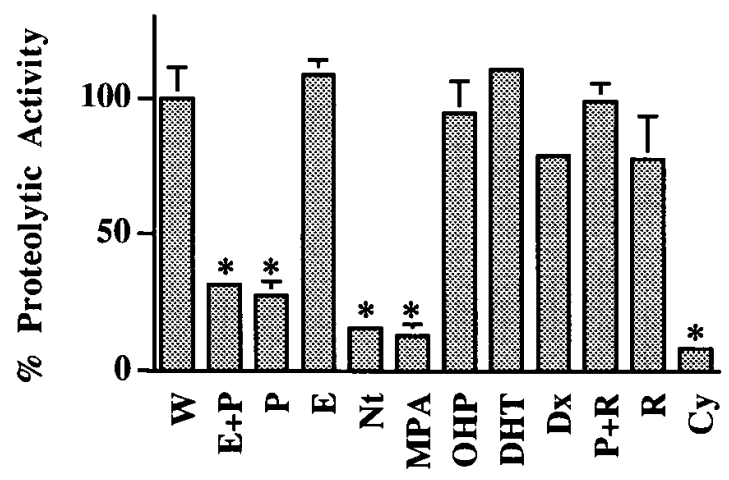

Figure 2. (A) Steroid-regulated proteolytic activity in stromal cultures. Stromal cells were cultured $14 \mathrm{~d}$ in EGF-supplemented serumfree medium containing no steroids $(C), 10 \mathrm{nM} \mathrm{E}(E), 1 \mu \mathrm{M} \mathrm{P}(P)$, or $10 \mathrm{nM} \mathrm{E}+1 \mu \mathrm{M} \mathrm{P}(E+\mathrm{P})$, followed by steroid withdrawal as described in Methods. Proteolytic activity of $2 \mathrm{~d}$-conditioned medium collected at the indicated times was assayed in the presence of 0.5 mM APMA. Values are the mean \pm SEM (bars) of duplicate cultures. (B) Progestin-specific regulation of proteolytic activity in stromal cultures. Stromal cells were cultured $12-14 \mathrm{~d}$ in serum-supplemented medium containing $30 \mathrm{nM} \mathrm{E}+0.3 \mu \mathrm{M} \mathrm{P}$, followed by steroid withdrawal as described in Methods. From the time of withdrawal control cultures received no additions $(W)$, and treatment groups received either $30 \mathrm{nM} \mathrm{E}+0.3 \mu \mathrm{M} \mathrm{P}(E+\mathrm{P}), 0.3-1 \mu \mathrm{M} \mathrm{P}(P), 30 \mathrm{nM} \mathrm{E}(E)$, $0.3-1 \mu \mathrm{M}$ norethindrone $(N t), 1 \mu \mathrm{M}$ medroxyprogesterone acetate $(M P A), 0.3-1 \mu \mathrm{M} 17 \alpha$-hydroxyprogesterone $(O H P), 30 \mathrm{nM}$ dexamethasone $(D x), 0.3 \mu \mathrm{M} \mathrm{P}+0.3 \mu \mathrm{M}$ RU486 $(P+\mathrm{R}), 1 \mu \mathrm{M}$ RU486 $(R)$, or $10-20 \mu \mathrm{M}$ cycloheximide $(C y)$. Proteolytic activity in 1 or 2 $\mathrm{d}$-conditioned media collected $4 \mathrm{~d}$ after hormonal withdrawal was assayed in the presence of $0.5 \mathrm{mM}$ APMA. All treatments were tested in duplicate cultures of at least two or three independent experiments, except MPA and R. Values are the mean \pm SEM (bars). Statistical significance of the differences between treatment and control groups were determined using one-way ANOVA and Dunnett's test for each experiment. Differences were not significant $(P>0.05)$ except where indicated $(* P<0.01)$.

of various steroid hormones, the progestin antagonist RU486, or the inhibitor of protein synthesis cycloheximide. Levels of proteolytic activity in APMA-activated conditioned media from the different treatment groups were compared to those of cultures in which steroids were withdrawn (Fig. 2 B). Cultures maintained in the presence of $\mathrm{E}+\mathrm{P}$ or receiving $\mathrm{P}$ alone after $\mathrm{E}+\mathrm{P}$ (i.e., E withdrawal) had significantly lower proteolytic activity $(P<0.01)$ than cultures in which both steroids were withdrawn. In contrast, proteolytic activity in cultures receiving $\mathrm{E}$ alone after $\mathrm{E}+\mathrm{P}$ (i.e., $\mathrm{P}$ withdrawal) was not significantly different $(P>0.05)$ from cultures in which both steroids were withdrawn. Other progestins such as norethindrone and medroxyprogesterone acetate, also reduced proteolytic activity in these experiments, whereas the less active $\mathrm{P}$ metabolite $17 \alpha$-hydroxyprogesterone, the androgen $5 \alpha$-dihydrotestosterone, and the glucocorticoid dexamethasone had no significant effects. Thus, withdrawal of $\mathrm{P}$, but not of $\mathrm{E}$, was the stimulus for metalloproteinase production in cultures that received combined treatment, and the induced proteolytic surge was effectively prevented by active progestational agents but not by other steroid hormones. In addition, proteinase production was stimulated by the P receptor antagonist RU486 in stromal cultures receiving continued $\mathrm{P}$ treatment $(\mathrm{P}+\mathrm{RU} 486)$ but was suppressed in cultures receiving cycloheximide from the time of steroid withdrawal. These studies indicated the stimulation of metalloproteinase production was a receptor-mediated, progestin-specific event involving de novo protein synthesis.

Identification of stromal cell proteinase. Conditioned medium from stromal cultures subjected to steroid withdrawal was analyzed by gelatin and casein substrate gel zymography. Using this technique, proteinases are separated by molecular size appearing as discrete, clear bands of substrate lysis. Latent metalloproteinases are also visualized on zymograms, as they are activated by SDS in these gels (36). Substrate gel analysis identified a major metalloproteinase in stromal cell-conditioned medium, present mostly as a latent $66-\mathrm{kD}$ proenzyme with lower levels of a $62-\mathrm{kD}$ active form. Casein zymography of conditioned medium showed no detectable activity after an overnight incubation (not shown). Gelatin zymograms revealed a major $66-\mathrm{kD}$ band of gelatinolytic activity and a minor $62-\mathrm{kD}$ component (Fig. $3 A$ ). Incubation of conditioned medium with APMA before zymography resulted in a marked increase of the $62-\mathrm{kD}$ species with reduction of the $66-\mathrm{kD}$ band. Gelatinolytic activity of the $66 / 62-\mathrm{kD}$ doublet was not affected by $p$-chloromercuribenzoate, PMSF, or pepstatin but was inhibited by 1,10-phenanthroline (Fig. $3 B$ ).
$\mathbf{A}$

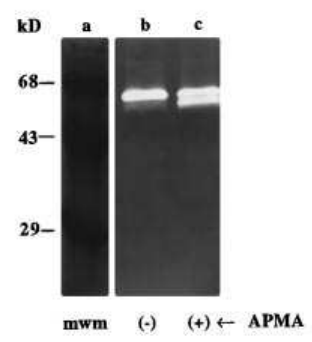

B

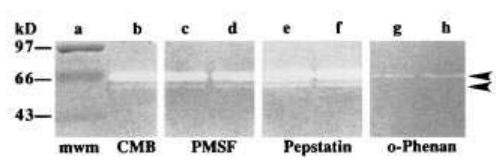

Figure 3. Substrate gel analysis of stromal cellconditioned medium. Stromal cells were cultured $12 \mathrm{~d}$ in serum-supplemented medium containing $30 \mathrm{nME}+$ $0.3 \mu \mathrm{M}$ P, followed by steroid withdrawal as described in Methods. $2 \mathrm{~d}$-conditioned medium collected $2 \mathrm{~d}$ after hormonal withdrawal was analyzed by gelatin zymography. (A) Conditioned medium was incubated at $37^{\circ} \mathrm{C}$ in the absence $(-$, lane $b)$ or presence $(+$, lane $c)$ of 1 mM APMA before zymography. $(B)$ After electrophoresis, the gel was divided into sections which were incubated in buffer containing either $5 \mathrm{mM}$ $p$-chloromercuribenzoate ( $C M B$, lane $b$ ), $5 \mathrm{mM}$ PMSF (lanes $c$ and $d$ ), $0.1 \mathrm{mM}$ pepstatin (lanes $e$ and $f$ ), or $5 \mathrm{mM}$ 1,10-phenanthroline (o-Phenan, lanes $g$ and $h$ ) before staining. Molecular weight markers $(\mathrm{mwm})$ are shown on lane $a$ in each panel. Arrows indicate the position of the bands of gelatin lysis. 
A

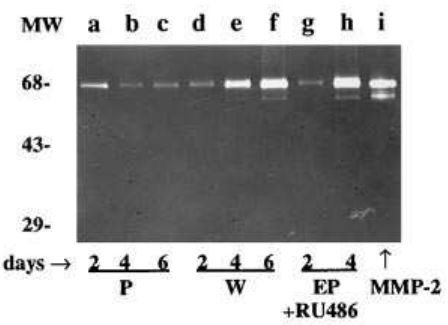

B

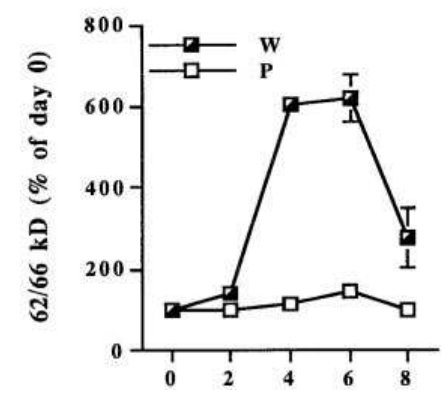

Figure 4. Hormonal regulation of gelatinase activity in stromal cellconditioned medium. Stromal cells were cultured $14 \mathrm{~d}$ in serum-free medium containing $10 \mathrm{nM} \mathrm{E}+1 \mu \mathrm{M} \mathrm{P}$, and for the following 6-8 d in the presence of no steroids $(W), 0.2 \mu \mathrm{M} \mathrm{P}$ $(P)$, or $10 \mathrm{nM} \mathrm{E}+0.2$ $\mu \mathrm{M} \mathrm{P}+1 \mu \mathrm{M}$ RU486 $(E P+\mathrm{RU} 486) \cdot(A)$ Gelatin zymogram of 2 d-conditioned media $(20 \mu \mathrm{l})$ collected 2,4 , and $6 \mathrm{~d}$ after the time of withdrawal (lanes $a-h$ ) and purified human MMP-2 (lane $i$ ). Position of the molecular weight markers $(M W)$ is

indicated on the left margin. (B) Integrative densitometry of the 66/ $62-\mathrm{kD}$ doublet on zymograms of $2 \mathrm{~d}$-conditioned media $(16 \mu \mathrm{l}) \mathrm{col}$ lected at the time of withdrawal (day 0 ) and every $2 \mathrm{~d}$ thereafter. Levels of 66/62-kD gelatinase in conditioned media were estimated running in parallel known amounts (0.5-20 ng) of purified MMP-2.

Values are the mean \pm SEM (bars) of duplicates cultures, expressed as a percentage of the mean value on day 0 .

The levels of $66 / 62-\mathrm{kD}$ gelatinase increased in stromal cultures after $\mathrm{P}$ withdrawal, coinciding with the upsurge of metalloproteinase activity. Fig. $4 A$ shows a gelatin zymogram of conditioned media from cultures exposed initially to $\mathrm{E}+\mathrm{P}$, followed by either steroid withdrawal, $\mathrm{P}$ alone, or $\mathrm{E}+\mathrm{P}+$ RU486. The bands of gelatinolytic activity detected in all conditioned media (lanes $a-h$ ) comigrated with purified MMP-2 (72-kD type IV collagenase/gelatinase A) (lane $i$ ). The intensity of both the 66- and 62-kD bands increased noticeably after $4 \mathrm{~d}$ of steroid withdrawal (lanes $d-f$ ), or addition of RU486 while continuing $\mathrm{E}+\mathrm{P}$ treatment (lanes $g-h$ ). In contrast, no increase of $66 / 62-\mathrm{kD}$ gelatinase activity was evident in cultures that received $\mathrm{P}$ alone after $\mathrm{E}+\mathrm{P}$ (lanes $a-c)$. In a similar experiment (Fig. $4 \mathrm{~B}$ ), densitometry showed a sixfold increase of the $66 / 62-\mathrm{kD}$ doublet on days 4 and 6 after steroid withdrawal, followed by a decline on day 8 , whereas in the presence of $\mathrm{P}$, $66 / 62-\mathrm{kD}$ gelatinase levels remained essentially unchanged. Similar results were obtained when norethindrone or medroxyprogesterone acetate $(0.3-1 \mu \mathrm{M})$ were used instead of $\mathrm{P}$, but no gelatin lysis bands were detectable when stromal cells were treated with cycloheximide $(10 \mu \mathrm{M})$ from the time of hormonal withdrawal (not shown).

The identity of the endometrial stromal cell metalloproteinase was confirmed using a specific MMP-2 antibody. Conditioned media from cells cultured in the absence of steroids, in the presence of $\mathrm{E}+\mathrm{P}$, or exposed initially to $\mathrm{E}+\mathrm{P}$, followed by either steroid withdrawal, addition of RU486, or treatment with $\mathrm{P}$ alone, were analyzed by Western immunoblotting. Under nonreducing conditions (Fig. $5 A$ ), a 66-kD band of immunoreactive MMP-2 was detected in cultures subjected to steroid withdrawal (lane $c$ ) but not in those receiving no steroids (lane $a$ ) or maintained in the presence of $\mathrm{E}+\mathrm{P}$ (lane $b$ ). Human fibroblast-conditioned medium was used as a
A

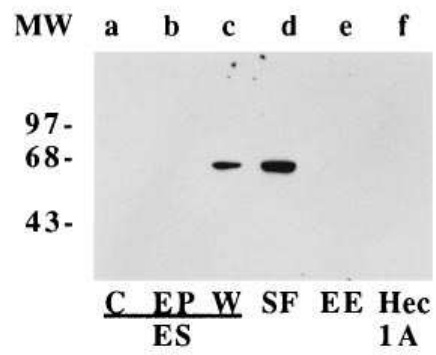

B

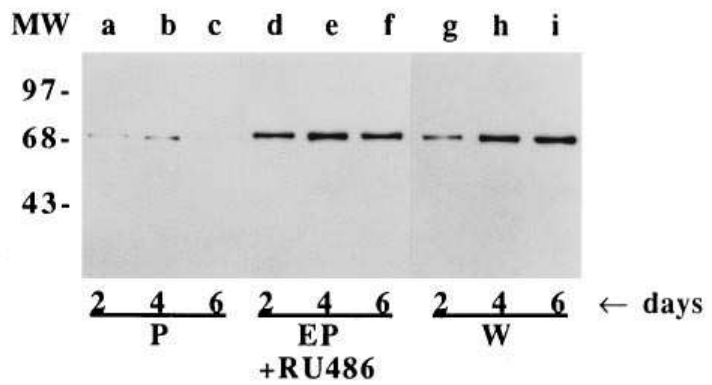

C

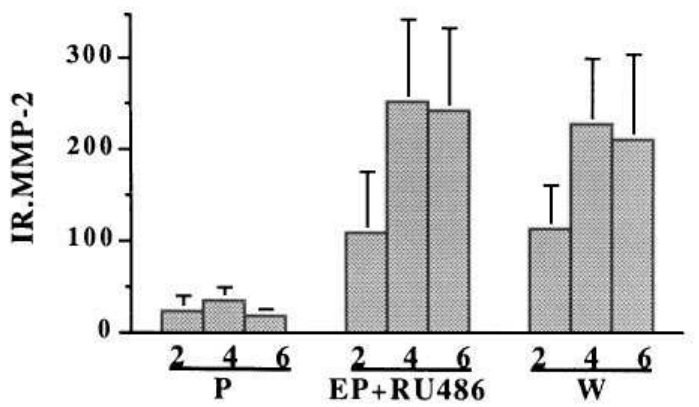

Figure 5. Western immunoblot analysis of MMP-2 in stromal cell cultures. Samples of $600 \mu \mathrm{l}(A)$ or $400 \mu \mathrm{l}(B)$ of $2 \mathrm{~d}$-conditioned media were concentrated, electrophoresed under nonreducing $(A)$ or reducing $(B)$ conditions, and analyzed by Western immunoblotting with anti-MMP-2. Position of the molecular weight markers $(M W)$ is indicated on the left margin. $(A)$ Stromal cells $(E S)$ were cultured $14 \mathrm{~d}$ in serum-free medium as described in Fig. 1, in the absence of steroids $(C$, lane $a)$, in the presence of $10 \mathrm{nM} \mathrm{E}+1 \mu \mathrm{M} \mathrm{P}(E P$, lane $b)$, or received $10 \mathrm{nM} \mathrm{E}+1 \mu \mathrm{M}$ P for $14 \mathrm{~d}$ followed by steroid withdrawal for $4 \mathrm{~d}(W$, lane $c)$. Human skin fibroblasts $(S F$, lane $d)$, human endometrial epithelial cells ( $E E$, lane $e$ ), and HEC-1A cells (lane $f$ ), received no steroids. ( $B)$ Stromal cells were cultured $14 \mathrm{~d}$ in serum-free medium containing $10 \mathrm{nME}+1 \mu \mathrm{M}$ P followed by $6 \mathrm{~d}$ in the presence of $0.2 \mu \mathrm{M} \mathrm{P}(P), 10 \mathrm{nM} \mathrm{E}+0.2 \mu \mathrm{M} \mathrm{P}+1 \mu \mathrm{M} \mathrm{RU} 486(E P+R U 486)$, or no steroids $(W)$, and conditioned media collected 2,4 , and $6 \mathrm{~d}$ after the time of withdrawal. $(C)$ Integrative densitometry of the $72-\mathrm{kD}$ MMP-2 band on Western blots of $2 \mathrm{~d}$-conditioned media collected 2, 4 , and $6 \mathrm{~d}$ after the time of withdrawal as described for $B$. Levels of immunoreactive MMP-2 (IR.MMP-2) in conditioned media were estimated running in parallel known amounts $(10-500 \mathrm{ng})$ of purified MMP-2. Values are the mean \pm SEM (bars) of measurements on two blots.

positive control (26) (lane $d$ ). Media from cultures of normal endometrial epithelial cells and from HEC-1A endometrial adenocarcinoma cells, neither of which showed bands of gelatin lysis in the 66-62 kD region by substrate gel analysis (not shown), were used as negative controls (lanes $e$ and $f$ ). Immunoreactive MMP-2, migrating at $72 \mathrm{kD}$ under reducing condi- 

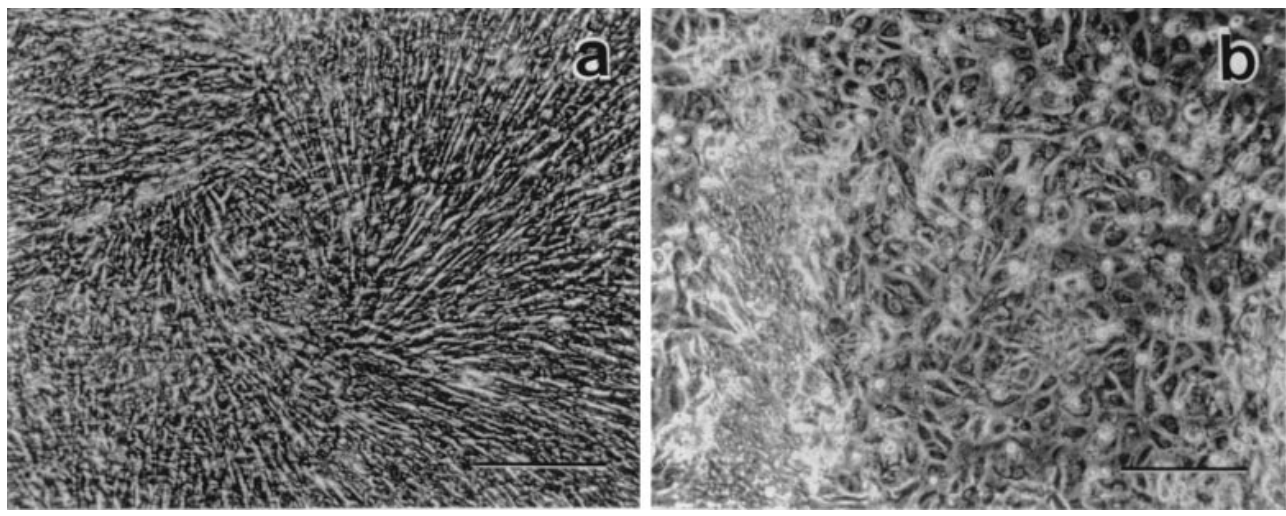

Figure 6. Steroid withdrawalinduced breakdown of human endometrial stromal cell cultures. Phase contrast micrographs of confluent cultures: $(a)$ maintained in serum-supplemented medium containing $10 \mathrm{nM} \mathrm{E}+$ $0.1 \mu \mathrm{M} P$ for $15 \mathrm{~d}$, or $(b)$ receiving $10 \mathrm{nME}+0.1 \mu \mathrm{M}$ P for $15 \mathrm{~d}$ followed by steroid withdrawal for $3 \mathrm{~d}$. Bar $=200 \mu \mathrm{m}$.

tions (Fig. $5 \mathrm{~B}$ ), was prominent in stromal cultures $2-6 \mathrm{~d}$ after steroid withdrawal (lanes $g-i$ ) or addition of RU486 while continuing $\mathrm{E}+\mathrm{P}$ treatment (lanes $d-f$ ), whereas cultures receiving $\mathrm{P}$ had low to undetectable levels of MMP-2 throughout this period (lanes $a-c$ ). Densitometric analysis (Fig. $5 C$ ) showed that 4-6 d after steroid withdrawal or addition of RU486, immunoreactive MMP-2 increased up to ninefold compared to
P-treated cultures, indicating MMP-2 levels increased concomitantly with metalloproteinase activity in stromal cultures after $\mathrm{P}$ withdrawal.

Morphological changes induced by hormonal withdrawal. The stimulation of MMP-2 secretion by $\mathrm{P}$ withdrawal was accompanied by the breakdown of stromal cell cultures. Confluent stromal cells formed multilayer cultures within 7-14 d
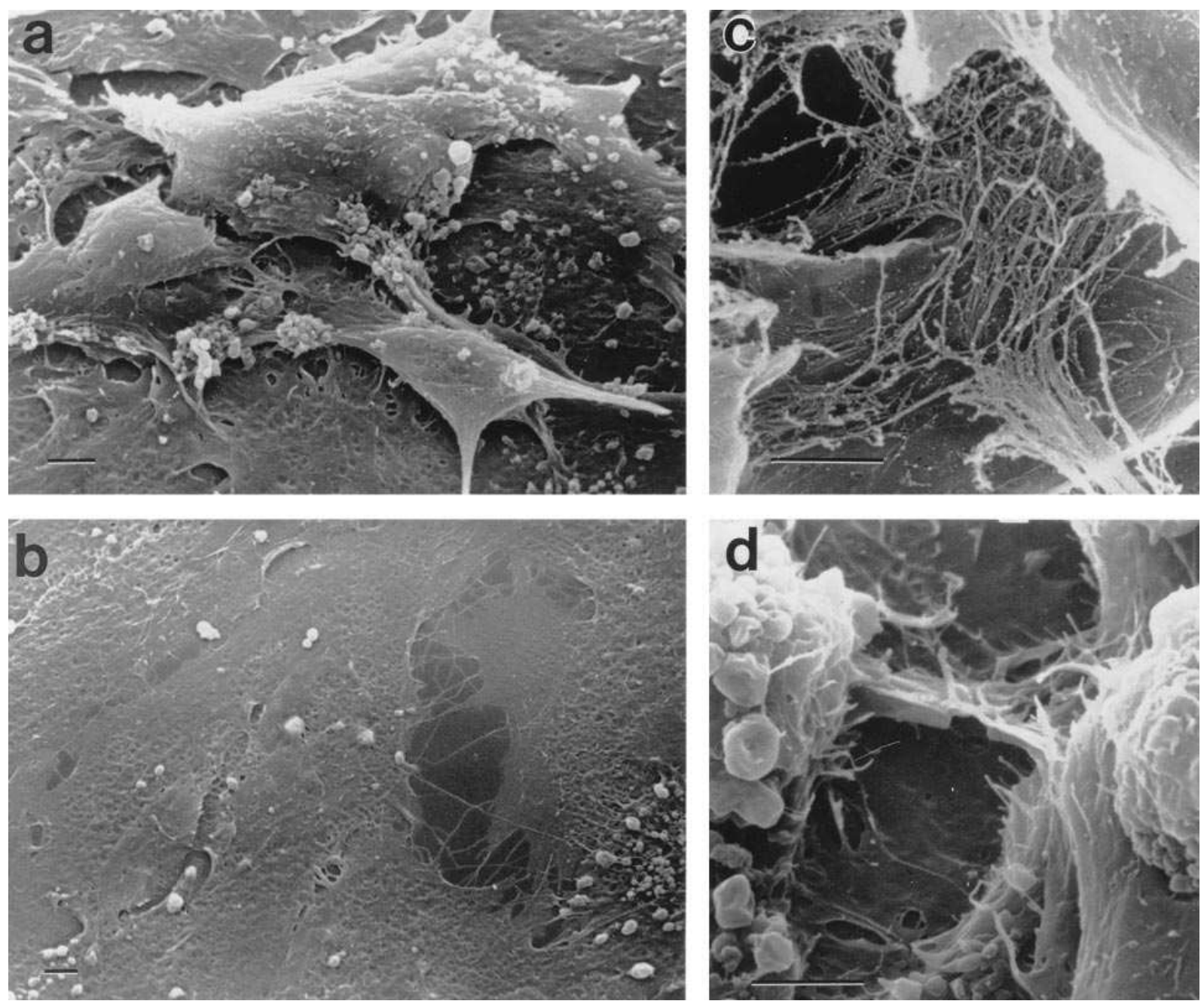

Figure 7. Steroid withdrawal-induced breakdown of human endometrial stromal cell cultures. Scanning electron micrographs of confluent cultures maintained in serum-supplemented medium containing $10 \mathrm{nM} \mathrm{E}+0.1 \mu \mathrm{M} \mathrm{P}$ for $14 \mathrm{~d}$, followed by steroid withdrawal for $3 \mathrm{~d}(a, b$, and $d)$ or receiving uninterrupted combined steroid treatment for $14 \mathrm{~d}(c)$. Bar $=2 \mu \mathrm{m}$. 
of continued exposure to $\mathrm{E}+\mathrm{P}$ (Fig. $6 a$ ). Steroid withdrawal was followed, after a lag of 2-4 d, by an abrupt breakdown of the multilayered cultures with shedding of the superficial cells (Fig. 6 b). Scanning electron microscopy of these cultures showed disruption of the multilayers with cells in the uppermost layers retracted and detached from neighboring cells (Fig. $7 a$ ), while most cells in the basal layer remained spread onto the plastic substrate (Fig. $7 \mathrm{~b}$ ). Most remarkably, the abundant fibrillar extracellular matrix produced by stromal cells under hormonal stimulation (Fig. $7 c$ ) was noticeably absent in the intercellular spaces after hormonal withdrawal (Fig. $7 d$ ).

The breakdown of stromal multilayers was specifically regulated by receptor-mediated progestin action and was dependent on metalloproteinase activity. In cultures receiving $\mathrm{E}+\mathrm{P}$, withdrawal of $\mathrm{P}$ (Fig. $8 a$ ), but not of $\mathrm{E}$ (Fig. $8 b$ ), induced multilayer breakdown. Addition of progestins, such as norethindrone or medroxyprogesterone acetate $(0.3-1 \mu \mathrm{M})$ after $\mathrm{E}+\mathrm{P}$ withdrawal, prevented stromal culture breakdown, whereas addition of the glucocorticoid dexamethasone $(30 \mathrm{nM})$ or the androgen $5 \alpha$-dihydrotestosterone $(0.1 \mu \mathrm{M})$ had no effect (not shown). Breakdown was also induced by addition of the $\mathrm{P}$ receptor antagonist RU486 to stromal cultures receiving P (Fig. $8 c$ ). Studies in which proteinase inhibitors were added from the time of steroid withdrawal, showed that breakdown was prevented by the broad-spectrum inhibitor $\alpha_{2}$-macroglobulin (200 $\mu \mathrm{g} / \mathrm{ml}$ ) (not shown), and by the metalloproteinase inhibitor 1,10-phenanthroline (Fig. $8 d$ ), but not by inhibitors of other proteinase classes (not shown) including soybean trypsin inhibitor $(100 \mu \mathrm{g} / \mathrm{ml})$, benzamidine $(1 \mathrm{mM})$, leupeptin $(3 \mathrm{mM})$, pepstatin $(1.5 \mu \mathrm{M}), \epsilon$-aminocaproic acid $(20 \mathrm{mM})$, and hirudin $(10 \mathrm{U} / \mathrm{ml})$. In addition, the breakdown of stromal cultures was dependent on protein synthesis, being prevented by the addition of cycloheximide $(10-20 \mu \mathrm{M})$ from the time of steroid withdrawal (not shown).

Expression of MMP-2 in human endometrium. To explore the possible physiological relevance of the in vitro findings described above, the expression of MMP-2 mRNA was examined in normally cycling endometrium. Northern analysis showed a single 2.9-kb transcript that hybridized to a 540-bp BamHI-EcoRI fragment of the MMP-2 cDNA in all the endometrial samples examined (Fig. $9 A$ ). A weak hybridization signal was found in RNA extracted from endometrial samples collected throughout the proliferative phase (lanes $a-d$ ), mid cycle (lane $e$ ), and early through mid secretory phase (lanes $f$ and $h)$. All three samples of late secretory endometrium (lanes $g, i$, and $j$ ) had a strong hybridization signal, but the transcript was barely detectable in early pregnancy decidua (lane $k$ ), and term placenta (lane $l$ ). To assess relative amounts of mRNA loaded in each lane, $\beta$-actin mRNA levels, which do not change in proliferative compared to secretory phase of the menstrual cycle (34), were used as an internal standard (Fig. $9 \mathrm{~B}$ ). To adequately compare the relative levels of MMP-2 mRNA in the various endometrial samples, autoradiograms of both the MMP- 2 and $\beta$-actin hybridizations were analyzed by densitometry, and the MMP-2 hybridization signal of each sample normalized to the respective $\beta$-actin level to correct for uneven loading. As shown in Fig. $9 C$, densitometric analysis confirmed an increase (2.5-4.9-fold) of the abundance of MMP-2 mRNA relative to $\beta$-actin mRNA lev-
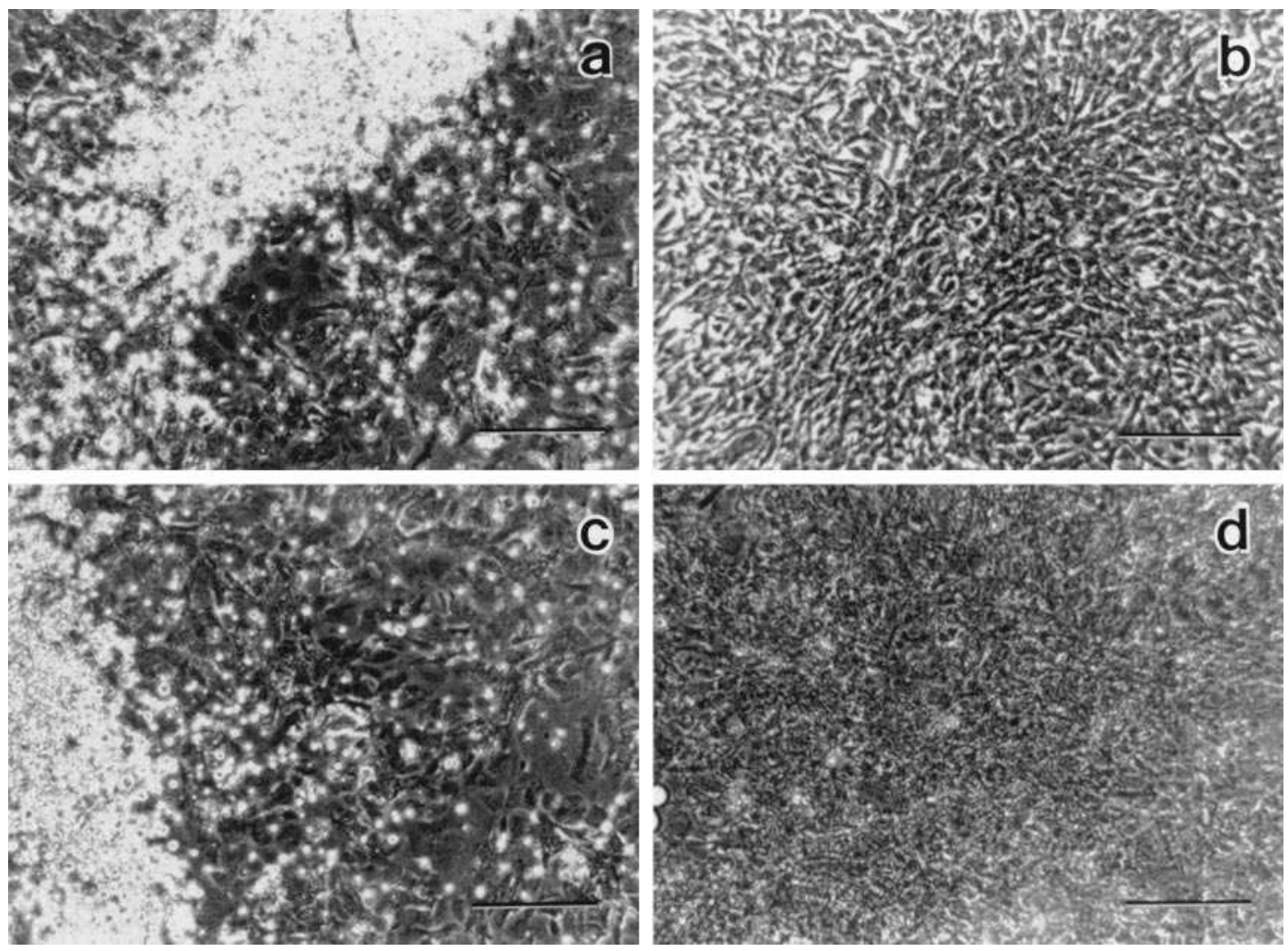

Figure 8. Effects of steroid hormones and inhibitors on the breakdown of stromal cell cultures. Confluent cultures were treated in serum-supplemented medium with $30 \mathrm{nM} \mathrm{E}+0.3 \mu \mathrm{M}$ P for $13 \mathrm{~d}$, followed by steroid withdrawal for $4 \mathrm{~d}$. From the time of withdrawal cultures received: $(a) 30$ nM E, (b) $0.3 \mu \mathrm{M} \mathrm{P},(c) 0.3 \mu \mathrm{M} \mathrm{P}+0.3 \mu \mathrm{M}$ RU486, (d) $25 \mu \mathrm{M}$ 1,10-phenanthroline. Bar $=200 \mu \mathrm{m}$. 
A MMP-2

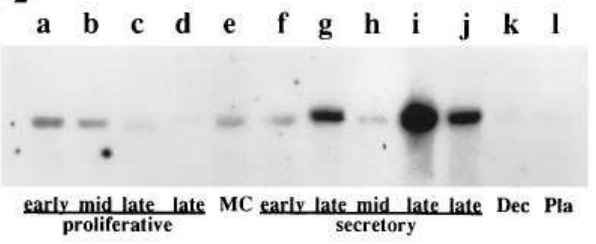

kb $-2.9$

B $\beta$-actin

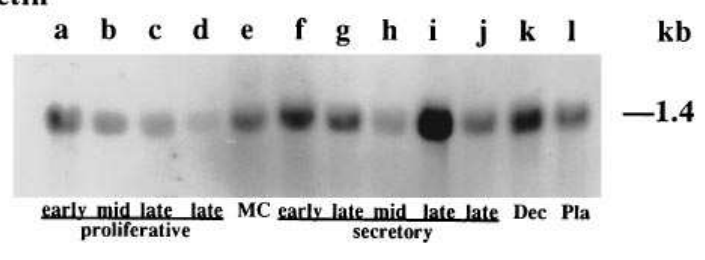

C Densitometry

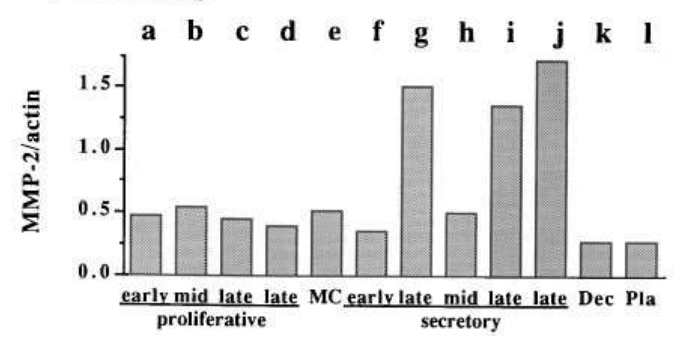

Figure 9. Expression of MMP-2 mRNA in human endometrium throughout the menstrual cycle. Samples of total RNA $(20 \mu \mathrm{g})$ extracted from the following tissues were analyzed by Northern blot hybridization: early, mid, and late proliferative endometrium (lanes $a-d)$; mid cycle endometrium (MC, lane $e$ ); early, mid, and late secretory endometrium (lanes $f-j$ ); early pregnancy decidua (Dec, lane $k$ ); term placenta (Pla, lane $l)$. (A) Autoradiograph of hybridization with the MMP-2 cDNA probe. (B) Autoradiograph of the same membrane hybridized with the $\beta$-actin cDNA probe. $(C)$ Densitometric analysis of the autoradiographs shown in $A$ and $B$, using the integrated area under the respective absorbance curves to calculate the MMP- $2 / \beta$-actin hybridization ratio for each sample.

els in all late secretory endometria compared to other phases of the cycle.

\section{Discussion}

The present study investigated the response of human endometrial stromal cells exposed in vitro to hormonal changes that mimic those preceding menstruation in vivo. $\mathrm{P}$ withdrawal, the physiologic stimulus for menstruation, induced MMP-2 secretion by stromal cells. Stromal cells maintained in the absence of steroid hormones did not produce constitutively high levels of MMP-2, and exposure to P followed by its withdrawal was required to stimulate MMP-2 secretion. MMP-2 production was stimulated by the $\mathrm{P}$ receptor antagonist RU486 but was suppressed by cycloheximide, indicating MMP-2 is specifically regulated by receptor-mediated progestin action, involving de novo protein synthesis. MMP-2 secretion was associated with a concomitant increase in metalloproteinase activity leading to the breakdown of the stromal cell multilayers. The breakdown of stromal cell cultures had remarkable similarities with the menstrual breakdown of the endometrium in vivo. Both occur within a few days of hormonal withdrawal, and involve the dissolution of extracellular matrix with dissociation of cellular elements. Consistent with the in vitro studies, Northern analysis showed MMP-2 mRNA expression increased in the decidualized endometrium of the late secretory phase, the time of declining $\mathrm{P}$ levels immediately preceding menstruation. These findings are in agreement with recent in situ hybridization studies showing a marked increase of MMP-2 mRNA expression in endometrial stromal cells in late secretory and early menstrual endometrium (21). Taken together, these observations suggest the response of stromal cells to steroid withdrawal in vitro may be relevant to endometrial cyclic activity.

In the present study, high expression of MMP-2 mRNA was restricted to the late secretory phase in cycling endometrium, but the transcript was almost undetectable in early pregnancy decidua, indicating that decidualization may be necessary but not sufficient to increase MMP-2 expression. These findings are consistent with a dual role of $\mathrm{P}$, both inducing competence for high MMP-2 production by promoting decidualization and directly inhibiting MMP-2 secretion by decidualized cells. Teleologically, the potential of decidualized cells to secrete a proteinase such as MMP-2 would endow the endometrium with the means of promoting the menstrual breakdown that is essential for restaging the ensuing cycle; however, this would not manifest in the event of pregnancy as elevated $\mathrm{P}$ levels would inhibit MMP-2 expression in the decidua. A role of MMP-2 in premenstrual/early menstrual events is consistent with recent in situ hybridization studies (21) showing MMP-2 mRNA is more widely distributed and more frequently detected than transcripts for stromelysin-2 (MMP-10) or stromelysin-3 in stromal cells of late secretory endometrium. However, in menstrual endometrium, mRNAs for interstitial collagenase (MMP-1), MMP-2, stromelysin 1 (MMP-3), matrilysin (MMP-7), 92-kD type IV collagenase/gelatinase B (MMP-9), MMP-10, and stromelysin-3 are detected with different tissue distributions, suggesting a more global and complex involvement of MMPs in the final breakdown and shedding of endometrial tissue.

MMP-2 was the major proteinase secreted by confluent cultures of decidualized endometrial stromal cells in response to $\mathrm{P}$ withdrawal in vitro. In contrast, previous studies showed that subconfluent cultures of stromal cells treated with phorbol myristate acetate secreted MMP-1, -2, -3, and -9 (20), and human endometrial explants released MMP-1, -2 , and -9 in a cycle-independent fashion, even though the release of all three MMPs was suppressed by P (19). The discrepancies between these and our findings may be attributed to significant differences in the culture conditions and treatment regimes used in each of the studies. In particular, the cellular complexity of unfractionated endometrial tissue, and the mechanical trauma inherent to explant culture experiments, may contribute to their inability to detect the complex hormonal regulation of MMP-2 seen in our defined cell culture system.

Endometrial stromal cell-derived MMP-2 shares the characteristics of MMP-2 produced by other human cells (30, 32, $35)$, being secreted as a $66-\mathrm{kD}(72-\mathrm{kD}$ reduced) proenzyme that generates a $62-\mathrm{kD}$ form after activation with the organomercurial APMA. The increase of metalloproteinase activity and immunoreactive MMP-2 detected after $\mathrm{P}$ withdrawal corresponded mostly to latent MMP-2, with lower levels of the active form. The reduced stability of the active form of MMP-2 (35) and presence of endogenous tissue inhibitors of metalloproteinases $(37,38)$ may contribute to the low levels of active 
enzyme detected. Low levels of active MMP-2 in conditioned media from stromal cultures undergoing breakdown may also result from the preferential localization of activated MMP-2 at the cell surface (39). Latent MMP-2 binds specifically to a still unidentified cell surface site (40) and is activated (41-43) by a recently described membrane-type MMP (44) that is an integral plasma membrane protein. Thus, our finding of a metalloproteinase-dependent breakdown of stromal cell multilayers is not only consistent with the involvement of MMP-2 in this process, but also raises the possibility that $\mathrm{P}$ withdrawal may induce the expression of MMP-2 binding sites and/or membrane-type MMP in stromal cells, thereby promoting MMP-2 activation.

The specific function of MMP-2 in the menstrual process and the physiological implications of stromal cells secreting this particular MMP await further study. Decidualized stromal cells produce an extracellular matrix containing types IV and $\mathrm{V}$ collagens as well as fibronectin and laminin (45, 46). MMP-2 degrades basement membrane collagens (types IV, V), fibronectin (32), and laminin (35) and may be expected to be actively involved in the degradation of extracellular matrix in decidualized endometrial stroma. In addition, MMP-2 is believed to play a role in processes which involve the breaching or remodeling of basement membranes, such as tumor invasion and angiogenesis (47). Therefore, stromal cell-derived MMP-2, by acting on components of the vascular and epithelial basement membranes, may be involved in breaching the integrity of the endometrial blood vessels and epithelial lining, leading to interstitial bleeding $(48,49)$ and passage of blood to the uterine cavity $(49,50)$.

The physiological process of menstruation encompasses diverse and complex changes that affect endometrial vascular function (51), extracellular matrix (52), prostaglandin production (53), and lysosomal enzymes (6). Current concepts on the mechanism of menstruation are still based largely on the observations of Markee half a century ago in rhesus monkeys (51). According to this model, the initiating event of menstruation is the intense vasospasm of the spiral arteries, which by causing ischemic damage to the vessel wall and the surrounding tissue leads to bleeding and breakdown of the stromal matrix. The essence of this hypothesis has not been seriously challenged since it was formulated, and research efforts have been directed at identifying vasoactive factors that may trigger the initiating vascular event, such as prostaglandins (reviewed in reference 54) or endothelins (55-57). The data presented herein support an alternative hypothesis whereby, independent of ischemia or hypoxia, decidualized endometrial stromal cells respond directly to $\mathrm{P}$ withdrawal and participate in the initiation of menstruation producing a proteinase that can act on the stromal extracellular matrix and on the vascular and epithelial basement membranes of the endometrium, thereby promoting endometrial breakdown and the onset of menstrual bleeding. Moreover, our finding of a $\mathrm{P}$ withdrawal-induced breakdown in cultures of isolated endometrial stromal cells provides experimental evidence suggesting that the vascular changes and the stromal breakdown that occur at the time of menstruation may be independent processes.

\section{Acknowledgments}

The authors thank B. A. Dsupin and H. Hyatt-Sachs for their skilled technical assistance, Dr. L. Boxer (Stanford University, Stanford, CA) for kindly providing the $\beta$-actin cDNA, and Dr. Y. Aladin Chandrasekher for critical review of the manuscript.

This work was supported by National Institutes of Health grant HD-25220 (to L. C. Giudice).

\section{References}

1. Noyes, R. W., A. T. Hertig, and J. Rock. 1950. Dating the endometrial biopsy. Fertil. Steril. 1:3-25.

2. Fraser, I. S. 1990. Mechanisms of endometrial bleeding. Reprod. Fertil. Dev. 2:193-198.

3. Rees, M. C. P., and A. C. Turnbull. 1989 Menstrual disorders: an overview. Balliere's Clinical Obstetrics and Gynaecology. 3:217-226.

4. Odlind, V., and I. S. Fraser. 1990. Contraception and menstrual bleeding disturbances: an overview. In Contraception and Mechanisms of Endometrial Bleeding. C. d'Arcangues, I. S. Fraser, J. R. Newton, and V. Odlind, editors. Cambridge University Press, Cambridge. 5-29.

5. Wood, J. C., A. E. Williams, V. L. Barley, and R. H. Cowdell. 1969. The activity of hydrolytic enzymes in the human endometrium during the menstrual cycle. J. Obstet. Gynaecol. Br. Commonw. 76:724-728.

6. Henzl, M. R., R. E. Smith, G. Boost, and E. T. Tyler. 1972. Lysosomal concept of menstrual bleeding in humans. J. Clin. Endocrinol. \& Metab. 34:860875 .

7. Cornellie, I., A. Brosens, E. Marbaix, T. Vael, P. Baudhuin, and P. J. Courtoy. 1990. A biochemical study of lysosomal enzymes in control and levonorgestrel-treated human endometria: analysis of total activity and evidence for secretion. In Contraception and Mechanisms of Endometrial Bleeding. C. d'Arcangues, I. S. Fraser, J. R. Newton, and V. Odlind, editors. Cambridge University Press, Cambridge. 383-410.

8. Vassalli, J.-D., A.-P. Sappino, and D. Belin. 1991. The plasminogen activator/plasmin system. J. Clin. Invest. 88:1067-1072.

9. Koutsky, J., M. Rybak, J. E. Jirasek, and J. Hladovec. 1969. The content of plasminogen activator in the endometrium, estimated by the fibrin-agar plate method. Gynecol. Invest. 167:257-263.

10. Werb, Z. 1985. Proteinases and matrix degradation. In Textbook of Rheumatology. W. N. Kelley, E. D. Harris, Jr., S. Rudy, and C. B. Sledge, editors. W. B. Saunders Co., Philadelphia. 300-321.

11. Woessner, J. F. 1991. Matrix metalloproteinases and their inhibitors in connective tissue remodeling. FASEB. J. 5:2145-2154.

12. Matrisian, L. M. 1990. Metalloproteinases and their inhibitors in matrix remodeling. TIG (Trends Genet.). 6:121-125.

13. Curry, T. E., D. D. Dean, J. F. Woessner, and W. J. LeMaire. 1985. The extraction of a tissue collagenase associated with ovulation in the rat. Biol. Reprod. 33:981-991.

14. Reich, R., A. Tsafriri, and G. L. Mechanic. 1985. The involvement of collagenolysis in ovulation in the rat. Endocrinology. 116:522-527.

15. Brenner, C. A., R. R. Adler, D. A. Rappolee, R. A. Pedersen, and Z. Werb. 1989. Genes for extracellular matrix-degrading metalloproteinases and their inhibitor, TIMP, are expressed during early mammalian development. Genes \& Dev. 3:848-859.

16. Woessner, J. F. 1979. Total, latent and active collagenase during the course of post-partum involution of the rat uterus. Biochem. J. 180:95-102.

17. Sellers, A., and J. F. Woessner. 1980. The extraction of a neutral metalloproteinase from the involuting rat uterus, and its action on cartilage proteoglycan. Biochem. J. 189:521-531.

18. Rodgers, W. H., K. G. Osteen, L. M. Matrisian, M. Navre, L. C. Giudice, and F. Gorstein. 1993. Expression and localization of matrilysin, a matrix metalloproteinase, in human endometrium during the reproductive cycle. Am. J. Obstet. Gynecol. 168:253-260.

19. Marbaix, E., J. Donnez, P. J. Courtoy, and Y. Eeckhout. 1992. Progesterone regulates the activity of collagenase and related gelatinases $\mathrm{A}$ and $\mathrm{B}$ in human endometrial explants. Proc. Natl. Acad. Sci. USA. 89:11789-11793.

20. Rawdanowicz, T. J., A. L. Hampton, H. Nagase, D. E. Wooley, and L. A. Salamonsen. 1994. Matrix metalloproteinase production by cultured human endometrial stromal cells: identification of interstitial collagenase, gelatinase-A, gelatinase-B, and stromelysin- 1 and their differential regulation by interleukin- $1 \alpha$ and tumor necrosis factor- $\alpha$. J. Clin. Endocrinol. \& Metab. 79: $530-536$.

21. Rodgers, W. H., L. M. Matrisian, L. C. Giudice, B. Dsupin, P. Cannon, C. Svitek, F. Gorstein, and K. G. Osteen. 1994. Patterns of matrix metalloproteinase expression in cycling endometrium imply differential functions and regulation by steroid hormones. J. Clin. Invest. 94:946-953.

22. Irwin, J. C., D. Kirk, R. J. B. King, M. M. Quigley, and R. B. L. Gwatkin 1989. Hormonal regulation of human endometrial stromal cells in culture: an in vitro model for decidualization. Fertil. Steril. 52:761-768.

23. Irwin, J. C., W. H. Utian, and R. L. Eckert. 1991. Sex steroids and growth factors differentially regulate the growth and differentiation of cultured human endometrial stromal cells. Endocrinology. 129:2385-2392.

24. Giudice, L. C., B. A. Dsupin, and J. C. Irwin. 1992. Sex steroid and peptide regulation of insulin-like growth factor-binding proteins secreted by human 
endometrial stromal cells is dependent on stromal differentiation. J. Clin. Endocrinol. \& Metab. 75:1235-1241.

25. Kirk, D., and J. C. Irwin. 1980. Normal human endometrium in cell culture. Methods Cell Biol. 21B:51-77.

26. Lechner, J. F., M. S. Babcock, M. Marnell, K. S. Narayan, and M. E. Kaighn. 1980. Normal human prostate epithelial cell cultures. Methods Cell Biol. 21B:195-225.

27. Woessner, J. F., and C. J. Taplin. 1988. Purification and properties of a small latent matrix metalloproteinase of the rat uterus. J. Biol. Chem. 263: $16918-16925$.

28. Herron, G. S., M. J. Banda, E. J. Clark, J. Gavrilovic, and Z. Werb. 1986. Secretion of metalloproteinases by stimulated capillary endothelial cells II: expression of collagenase and stromelysin activities is regulated by endogenous inhibitors. J. Biol. Chem. 261:2814-2818.

29. Laemmli, U. K. 1970. Cleavage of structural proteins during the assembly of the head of the bacteriophage T4. Nature (Lond.). 227:680-685.

30. Stetler-Stevenson, W. G., H. C. Krutzsch, M. P. Wacher, I. M. K. Margulies, and L. A. Liotta. 1989. The activation of human type IV collagenase proenzyme: sequence identification of the major conversion product following organomercurial activation. J. Biol. Chem. 264:1353-1356.

31. Towbin, H., T. Staehelin, and J. Gordon. 1979. Electrophoretic transfer of proteins from polyacrylamide gels to nitrocellulose sheets: procedure and some applications. Proc. Natl. Acad. Sci. USA. 76:4350-4353.

32. Collier, I. E., S. M. Wilhem, A. Z. Eisen, B. L. Marmer, G. A. Grant, J. A. Seltzer, A. Kronberger, C. He, E. A. Bauer, and G. I. Goldberg. 1988. H-ras oncogene-transformed human bronchial epithelial cells (TBE-1) secrete a single metalloprotease capable of degrading basement membrane collagen. J. Biol. Chem. 263:6579-6587.

33. Cathala, G., J. F. Savouret, B. Mendez, B. L. West, M. Karin, J. A. Martial, and J. D. Baxter. 1983. A method for isolation of intact, translationally active ribonucleic acid. $D N A(N Y)$. 2:329-335.

34. Giudice, L. C., D. A. Milkowsky, G. Lamson, R. G. Rosenfeld, and J. C. Irwin. 1991. Insulin-like growth factor binding proteins in human endometrium: steroid-dependent messenger ribonucleic acid expression and protein synthesis. J. Clin. Endocrinol. \& Metab. 72:779-787.

35. Okada, F., T. Morodomi, J. J. Enghild, K. Suzuki, A. Yasui, I. Nakanishi, G. Salvesen, and H. Nagase. 1990. Matrix metalloproteinase 2 from human rheumatoid synovial fibroblasts: purification and activation of the precursor and enzymic properties. Eur. J. Biochem. 194:721-730.

36. Birkedal-Hansen, H., and R. E. Taylor. 1982. Detergent-activation of latent collagenase and resolution of its component molecules. Biochem. Biophys. Res. Commun. 107:1173-1178.

37. Stetler-Stevenson, W. G., H. C. Krutzsch, and L. A. Liotta. 1989. Tissue inhibitor of metalloproteinase (TIMP-2): a new member of the metalloproteinase inhibitor family. J. Biol. Chem. 264:17374-17378.

38. Goldberg, G. I., B. L. Marmer, G. A Grant, A. Z Eisen, S. Wilhem, and C. He. 1989. Human 72-kilodalton type IV collagenase forms a complex with a tissue inhibitor of metalloproteinases designated TIMP-2. Proc. Natl. Acad. Sci. USA. 86:8207-8211.

39. Monsky, W. L., S. C. Kelly, C.-Y. Lin, Y. Yeh, W. G. Stetler-Stevenson, S. C. Mueller, and W. T. Chen. 1993. Binding and localization of $M_{r} 72,000$ matrix metalloproteinase at cell surface invadopodia. Cancer Res. 53:3159-3164.

40. Emonard, H. P., A. G. Remacle, A. C. Noel, J.-A. Grimaud, W. G. Stetler-Stevenson, and J.-M. Foidart. 1992. Tumor cell surface-associated bind- ing site for the $\mathrm{M}_{\mathrm{r}}$ 72,000 type IV collagenase. Cancer Res. 52:5845-5848.

41. Overall, C., and J. Sodek. 1990. Concanavalin A produces a matrix-degradative phenotype in human fibroblasts. J. Biol. Chem. 265:21141-21151.

42. Brown, P. D., A. T. Levy, I. M. K. Margulies, L. A. Liotta, and W. G. Stetler-Stevenson. 1990. Independent expression and cellular processing of $\mathrm{M}_{\mathrm{r}}$ 72,000 type IV collagenase and interstitial collagenase in human tumorigenic cell lines. Cancer Res. 50:6184-6191.

43. Brown, P. D., D. E. Kleiner, E. J. Unsworth, and W. G. Stetler-Stevenson. 1993. Cellular activation of the $72 \mathrm{kDa}$ type IV collagenase/TIMP-2 complex. Kidney Int. 43:163-170.

44. Sato, H., T. Takino, Y. Okada, J. Cao, A. Shinagawa, E. Yamamoto, and M. Seiki. 1994. A matrix metalloproteinase expressed on the surface of invasive tumor cells. Nature (Lond.). 370:61-65.

45. Wewer, U. M., M. Faber, L. A. Liotta, and R. Albrechtsen. 1985. Immunocytochemical and ultrastructural assessment of the nature of the pericellular basement membrane of human decidual cells. Lab. Invest. 53:624-633.

46. Kisalus, L. L., J. C. Herr, and C. D. Little. 1987. Immunolocalization of extracellular matrix proteins and collagen synthesis in first-trimester human decidua. Anat. Rec. 218:402-415.

47. Liotta, L. A., P. S. Steeg, and W. G. Stetler-Stevenson. 1991. Cancer metastasis and angiogenesis: an imbalance of positive and negative regulation. Cell. 64:327-336.

48. Cornellie, F. J., J. M. Lauweryns, and I. A. Brosens. 1985. Normal human endometrium: an ultrastructural survey. Gynecol. Obstet. Invest. 20:113129 .

49. Flowers, C. E., and W. H. Wilborn. 1979. Histoenzymology of the human endometrium during menstruation (II). In The Biology of the Fluids of the Female Genital Tract. F. K. Beller, and G. F. B. Schumacher, editors. Elsevier Science Publishing Co., New York. 203-223.

50. Wagner, H., and F. K. Beller. 1979. Ultrastructural aspects of human endometrium during menstruation. In The Biology of the Fluids of the Female Genital Tract. F. K. Beller, and G. F. B. Schumacher, editors. Elsevier Science Publishing Co., New York,187-201.

51. Markee, J. E. 1940. Menstruation in intraocular endometrial transplant in the rhesus monkey. Contrib. Embryol. Carnegie Inst. 28:219-308.

52. Flowers, C. E., and W. H. Wilborn. 1978. New observations on the physiology of menstruation. Obstet. Gynecol. 51:16-24.

53. Singh, E. J., I. M. Buccarini, and F. P. Zuspan. 1975. Levels of prostaglandins $\mathrm{F} 2 \alpha$ and $\mathrm{E}$ in human endometrium during the menstrual cycle. Am. J. Obstet. Gynecol. 121:1003-1006.

54. Smith, S. K. 1990. The role of eicosanoids in menstruation and disorders of menstruation. In Eicosanoids in Reproduction. M. D. Mitchell, editor. CRC Press Inc., Boca Raton, FL. 87-102.

55. Mitchel, M. D. 1992. Endothelins and dysfunctional uterine bleeding. In Steroid Hormones and Uterine Bleeding. N. J. Alexander, and C. d'Arcangues, editors. AAAS Press, Washington, DC. 193-200.

56. Findlay, J. K., A. L. Hampton, A. R. Butt, and L. A. Salamonsen. 1992. Endothelin in the human endometrium. In Steroid Hormones and Uterine Bleeding. N. J. Alexander, and C. d'Arcangues, editors. AAAS Press, Washington, DC. 201-208.

57. Casey, M. L., and P. C. MacDonald. 1992. Modulation of endometrial blood flow: regulation of endothelin-1 biosynthesis and degradation in the human endometrium. In Steroid Hormones and Uterine Bleeding. N. J. Alexander, and C. d'Arcangues, editors. AAAS Press, Washington, DC. 209-224. 